\section{Moving toward sustainable fishing practices in Tenerife}

Artisanal fishing is commonplace on the island of Tenerife, however, the local fisheries are unsustainable. The Canary Island government is mandated to implement the the European Commission's Common Fisheries Policy, but it has yet to do so. The authors convened a number of focus groups with members of local fishing communities (Cofradías), public administrators, and civil society organizations to crowdsource the current problems with the local fishery and solutions to make it more sustainable.

During these focus groups, participants first mapped problem trees to help visualize and organize problems and their effects. For example, one problem tree mapped no institutional coordination as the source to the lack of marine reserves, which in turn leads to an unsustainable fishery. The unsustainable fishery was mapped to causing fewer fish in the sea, leading to environmental deterioration.

Unlike other nearby islands, Tenerife has not established any marine protected areas (MPAs) due to historical conflicts been local groups. The lack of MPAs was pointed out many times during the focus groups as one of the main reasons for the island's unsustainable fisheries.

Difficulties in commercializing fishery products, like selling locally-caught fish to local restaurants, was also highlighted as a top problem.

After mapping problem trees, participants then mapped solution trees to conceptualize ways to mitigate these problems. Marine reserves and surveillance/control mechanisms were common solutions. In addition to these, participants suggested establishing seasonal regulations for recreational fisheries, promoting dialogue between scientists and the recreational fishing communities, and education/training opportunities for all those involved in fishing activities - including fishers, regulators, and the public.

Illegal fishing was brought up as a common problem on the island. To combat this threat, it was proposed that Cofradías should create oversight groups in coordination with the marine guard. Specific branding for artisanal fishery products was also suggested as a solution to properly label legally-caught fish, which could help with commercialization problems.
This is a summary of: Local community-based approach for sustainable management of artisanal fisheries on small islands

Accessible at: https://marxiv.org/n7cve

Authors:

Serafín Corral, David

Romero Manrique

Added to MarXiv:

April 2018

Published: Marine Policy, 2017

Suggested Citation: Moving toward sustainable fishing practices in Tenerife. OCTO (2018). DOI:

10.17605/OSF.IO/VKNA8

See more MarXiv summaries at https://www.marxivinfo.org/ summaries

Join the MarXiv Summaries monthly newsletter at https:// oct.to/marxivsum

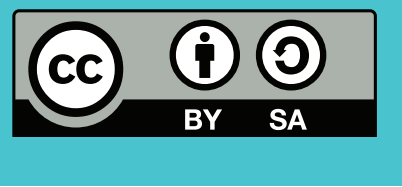

MarXiv is an ОСТO Initiative
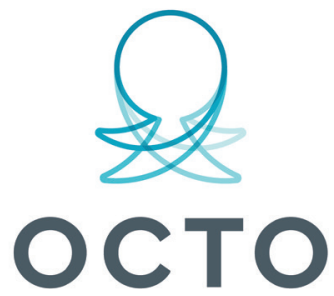

OPEN COMMUNICATIONS FOR THE OCEAN 